\title{
Endometriosis in MRKH cases as a proof for the coelomic metaplasia hypothesis?
}

\author{
Lutz Konrad, Raimund Dietze, Pradeep Kumar Kudipudi, Fabian Horné and \\ Ivo Meinhold-Heerlein \\ Institute of Gynecology and Obstetrics, Giessen, Germany \\ Correspondence should be addressed to L Konrad; Email: Lutz.Konrad@gyn.med.uni-giessen.de
}

\begin{abstract}
A diagnosis of endometriosis is based upon the histological identification of endometrial tissue at ectopic sites which are commonly located on the pelvic organs, the peritoneum and ovary. In rare cases, ectopic lesions can be found in other organs, such as kidney, bladder, lung or brain. Diagnosis is achieved by laparoscopic intervention followed by histological confirmation of endometriotic tissue. Prevalence is estimated at approximately $10 \%$ in the general female population with many patients experiencing pain and/or infertility. Currently, the implantation hypothesis by Sampson is the most accepted hypothesis about the pathogenesis of endometriosis. However, the occurrence of endometriosis in patients with Mayer-Rokitansky-Küster-Hauser (MRKH) syndrome who sometimes lack a uterus or endometrium seems to suggest metaplasia as a cause of endometriosis. A critical reevaluation of the literature about MRKH does not reveal conclusive evidence of an association of uterus/endometrium agenesis and endometriosis. Most often only MRI diagnoses of uterus/endometrium agenesis and only very rarely conclusive histological evidence of the endometriotic lesions are presented. In contrast, whenever biopsies were performed endometriosis always appeared together with uterus/endometrium remnants. Taken together, we suggest that MRKH patients only develop endometriosis if a uterus/endometrium is present which underscores and not contradicts the implantation hypothesis of Sampson.

Reproduction (2019) 158 R41-R47
\end{abstract}

\section{Introduction}

In its simplest definition endometriosis is a disease characterized by the presence of endometrial glands and stroma outside of the normal localization (Clement 2007). Furthermore, irrespective of location, endometriotic glands almost always have an overtly endometrioid appearance and histologically resemble uterine endometrial glands (Clement 2007). Despite this straightforward histological definition, it is puzzling that endometriosis and endometriotic lesions show so many different facets, such as variations in color, depth of invasion, adhesions, ovarian cysts and different epithelial-to-stromal cell ratios up to the extreme case of stromal endometriosis (Guo 2018).

Retrograde menstruation followed by implantation of the endometrial tissue on different surfaces in the pelvic or abdominal cavity is generally accepted as the main cause of endometriosis (Sampson 1927). Despite the high rate of retrograde menstruation, only approximately $10 \%$ of women in their reproductive age acquire endometriosis (Bulun 2009) pointing to secondary factors affecting the adhesion and invasion of endometrial cells thus resulting in endometriosis. It has been hypothesized that peritoneal endometriosis, endometriomas and deep-infiltrating endometriosis
(DIE) could represent three distinct entities, which do not share a common pathogenesis (Nisolle \& Donnez 1997). Especially ovarian endometriosis (endometriomas) was postulated to be derived from metaplasia (Zheng et al. 2005).

Robert Meyer (1924) was the first to introduce the hypothesis that endometriosis may arise from coelomic epithelium. The female reproductive tract develops from a pair of Müllerian ducts, which arise from coelomic epithelial cells of mesodermal origin (Kurita 2011; Fig. 1). Then the Müllerian ducts undergo a transformation from single tubes consisting of homogeneous epithelium and surrounding mesenchyme into several distinct organs, namely the oviduct, uterus, cervix and vagina. The underlying mesenchyme hereby dictates the organspecific cell fate of the coelomic epithelium. However, we should keep in mind, that the ovaries only contain remnants from the coelomic epithelium in form of the mesothelial surface. In mature reproductive tracts, the developmental plasticity of coelomic epithelial cells is mostly lost (Kurita 2011; Fig. 1).

In endometriosis, the process of metaplasia is postulated to involve the transdifferentiation of a committed cell type (e.g. mesothelium) into an alternative cell type (e.g. endometrial epithelium). Recently, 

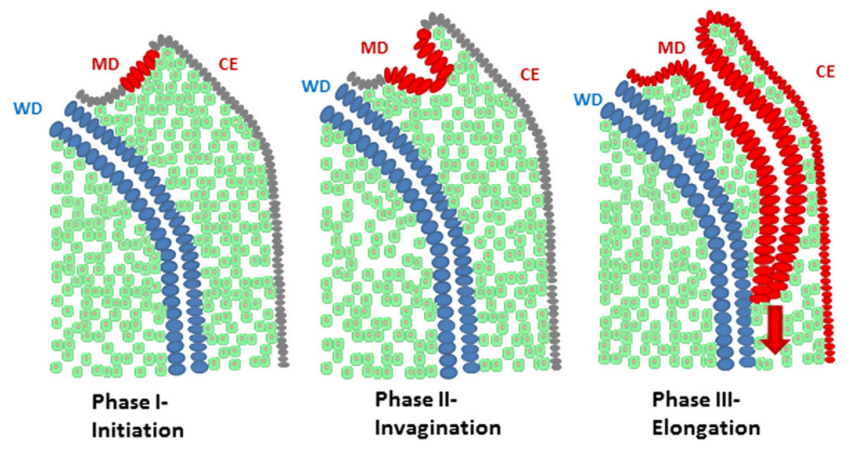

Figure 1 Development of the Müllerian duct (MD) and coelomic epithelium (CE). The MD arises as a local thickening (phase I) and CE invagination (phase II) at the cranial end of the urogenital ridge. The MD grows caudally (phase III, arrow) through the mesenchyme of the urogenital ridge and the tip comes into contact with the Wolffian duct (WD). The MD develops to the vagina (parts), cervix, uterus and oviduct; the CE develops to peritoneum and mesothelial surface cells (OSE) on the ovary.

metaplasia was also suggested for abdominal wall endometriosis (Ibrahim et al. 2017) and adenomyosis (García-Solares et al. 2018).

\section{Methods}

A search was carried out using Medline. Key words for the search were 'Mayer-Rokitansky-Kuster-Hauser' or 'MRK' in combination with 'uterus', 'endometrium' 'endometriosis', 'adenomyosis', 'metaplasia' in combination with 'MRKH', 'endometriosis' and 'adenomyosis' and 'ovarian metaplasia'. Each manuscript was downloaded and the histological evidences presented for the uterus, and eutopic and ectopic endometrium were evaluated. A summary of all reports dealing with MRKH together with endometriosis or adenomyosis can be found in Table 1.

\section{Basic features of MRKH}

The MRKH syndrome is named after August Franz Joseph Karl Mayer, Karl Freiherr von Rokitansky, Hermann Küster and Georges Andre Hauser; each of their observations have contributed to the discovery and definition of this disease (Patnaik et al. 2015). The incidence of MRKH is estimated to be 1 in 4000-5000 female newborns (Ledig \& Wieacker 2018). Patients with MRKH typically have a normal ovarian function and a normal karyotype; however, a congenital aplasia of the vagina, cervix and uterus is often observed (Oppelt et al. 2012, Pan \& Luo 2016, Wang et al. 2017). In the vast majority of cases primary amenorrhea leads to the initial presentation (Ledig \& Wieacker 2018). MRKH is generally divided into two subtypes: MRKH type 1 , in which only the upper vagina, cervix and uterus are affected, and MRKH type 2, which is associated with additional malformations affecting the renal and skeletal system (Londra et al. 2015). Most of the MRKH cases are sporadic, but analyses of the few reported familial cases suggest an autosomal-dominant inheritance with reduced penetrance (Ledig \& Wieacker 2018). Up to date the etiology of MRKH is still unresolved (Rall et al. 2013, Ledig \& Wieacker 2018). Although treatment options for MRKH are scarce (Londra et al. 2015), recently, treatment with a tissueengineered vagina has gained some attention (Raya-Rivera et al. 2014).

\section{Uterus and endometrium in MRKH patients}

Several studies with large cohorts of MRKH cases showed that $48-99.2 \% \mathrm{MRKH}$ patients still have a rudimentary uterus (Oppelt et al. 2012, Hall-Graggs et al. 2013, Marsh et al. 2013, Rall et al. 2013, Preibsch et al. 2014, Lalatta et al. 2015, Pan \& Luo 2016, Wang et al. 2017). In three studies (Oppelt et al. 2012, Lalatta et al. 2015, Pan \& Luo 2016) the numbers of aplastic uteri are not clearly specified. Most often magnetic resonance imaging (MRI) and ultrasound have been used to evaluate the presence of the uterus (Table 1). It is generally agreed that MRI is the modality of choice for further evaluation of all uterine anomalies (Londra et al. 2015). In a case series of MRKH patients $(n=214)$ an overall correlation above $95 \%$ between MRI and laparoscopic findings was reported for 115 patients (Preibsch et al. 2014), which included $75 \%$ of patients with bilateral uterine rudiments, $15 \%$ with unilateral uterine rudiments and only $10 \%$ with complete uterine agenesis. In $85 \%$ of cases where uterine rudiments were removed, the presence of endometrial tissue was adequately diagnosed by MRI (Preibsch et al. 2014); however, 15\% of endometria were missed by MRI.

Histological analysis from biopsies of MRKH patients demonstrated an endometrium in 40.5\% (17/42; Rall et al. 2013), in 48\% (23/48; Marsh et al. 2013) and in 100\% (9/9; Wang et al. 2017) of the cases.

\section{MRKH and endometriosis}

In PubMed we searched for articles describing an association between MRKH and endometriosis. We identified 21 manuscripts, 19 of which were case reports (Table 1). Most of the authors identified MRKH by MRI and/or ultrasound and presented some evidence of endometriosis, especially of ovarian endometriosis and adenomyosis. Interestingly, in 7 out of 18 articles describing uterus remnants also endometria could be identified (Table 1). It remains unclear whether in the ten articles with uterine remnants, endometria were missed, because these assumptions were mostly based upon MRI or ultrasound. As shown in a comparative study, MRI detection of uterine remnants agreed in $77.3 \%$ with laparoscopy (Preibsch et al. 2014), thus demonstrating that MRI is not sufficient to prove the absence of uterus remnants. Additionally, the sensitivity of ultrasound in the detection of uterine remnants is even lower (Lermann et al. 2011).

Remarkably, in only 11 articles a biopsy of the uterus was undertaken and only three manuscripts presented histologic evidence of uterus/endometrium (Table 1). Furthermore, in only five articles histology of the endometriotic lesions was presented (Table 1). Enatsu et al. (2000) showed an endometrial/adenomyotic gland, but without an identifiable myometrium and the whole uterus not shown, the evaluation of adenomyosis is not conclusive (Fig. 2A, B and C). Furthermore 


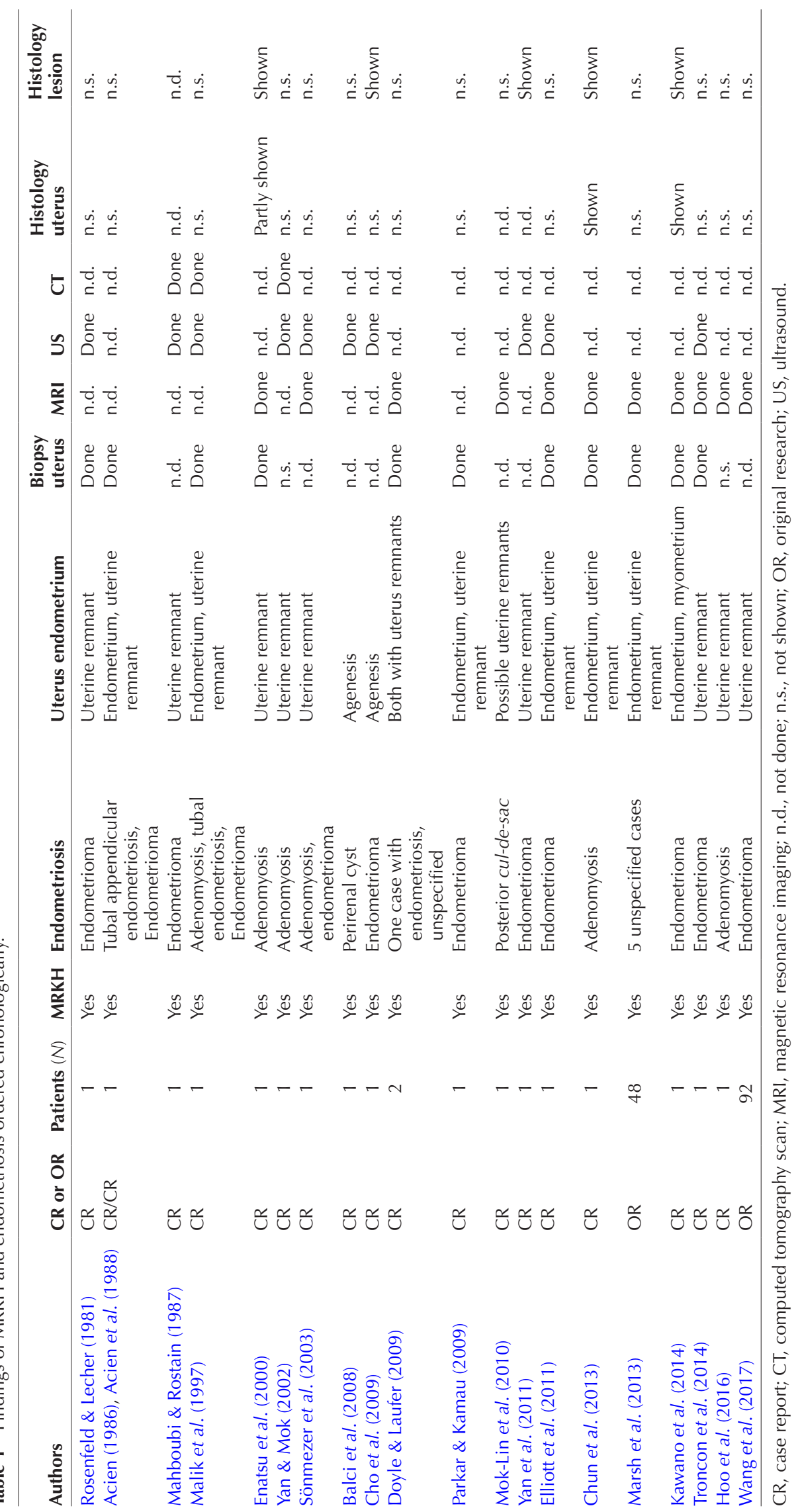



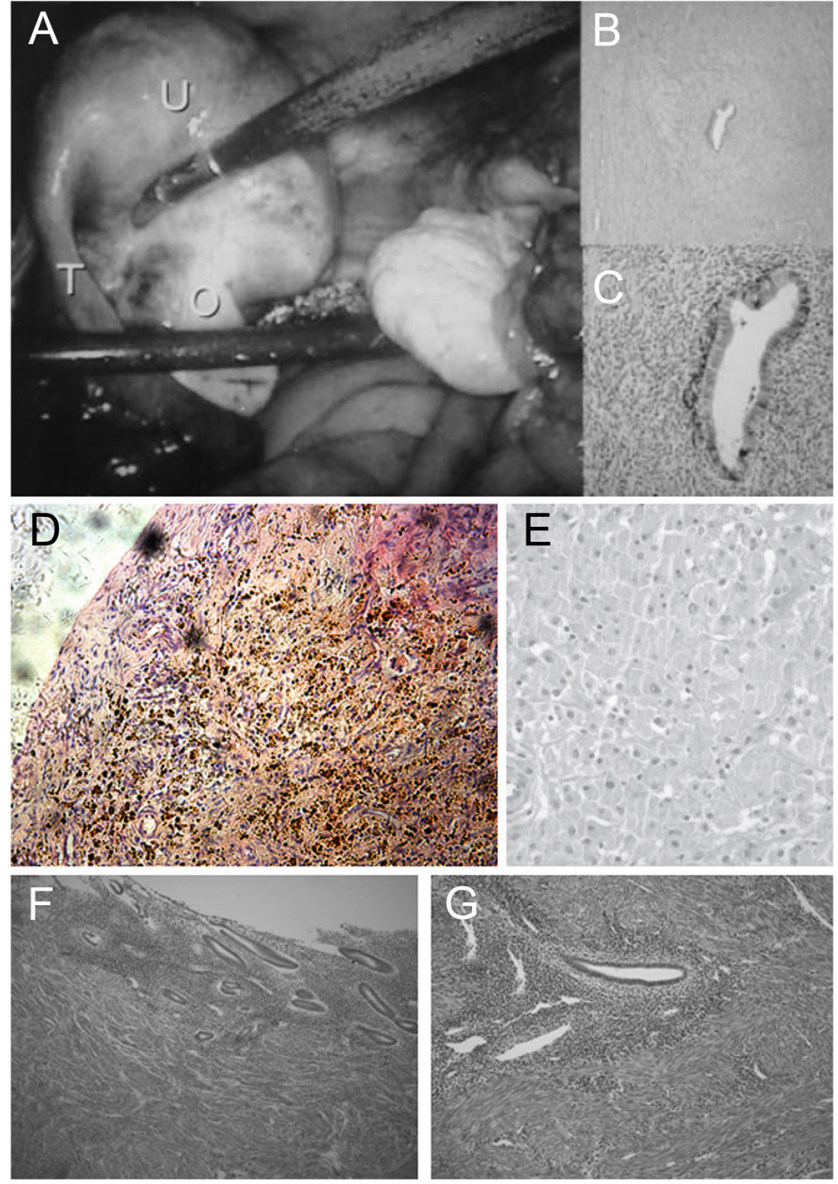

Figure 2 Photographs of MRKH cases associated with endometriosis. Enatsu et al. (2000) isolated from a laparoscopy (A) uterus remnants ( $\mathrm{B}$ and $\mathrm{C}$ ) and described the gland as adenomyosis. However, no myometrium is recognizable and the whole uterus is not shown. Yan et al. (2011) presented a case of ovarian endometriosis (D) of an MRKH patient; however, no cysts or glands are visible. Similarly, Cho et al. (2009) also showed a cyst of ovarian endometriosis (E) of an MRKH patient; however, no cyst is visible. In contrast, Chun et al. (2013) presented a normal endometrium (F) and an adenomyosis (G) of an MRKH patient.

the diagnosis of adenomyosis in MRKH patients is debatable because endometrial islands have been described as typical for MRKH patients (Ledig \& Wieacker 2018).

In the figures presented by Yan et al. (2011; Fig. 2D) and Cho et al. (2009; Fig. 2E), no ovarian lesions are visible. Only Chun et al. (2013) presented histological evidence of endometrium and adenomyosis in one MRKH case (Fig. 2F and G). Marsh et al. (2013) observed in five MRKH patients an endometrium $(100 \%)$ and reported also endometriosis, but did not describe the location. This was further substantiated by Will et al. (2013) with the same patient subgroup; however, histological evidence was again not presented. In contrast, despite a negative MRI for uterus remnants, Kawano et al. (2014) showed an endometrium, myometrium and an endometriotic cyst after laparoscopy.

Despite these shortcomings, most of the authors claimed to have proven endometriosis without uterus/endometrium
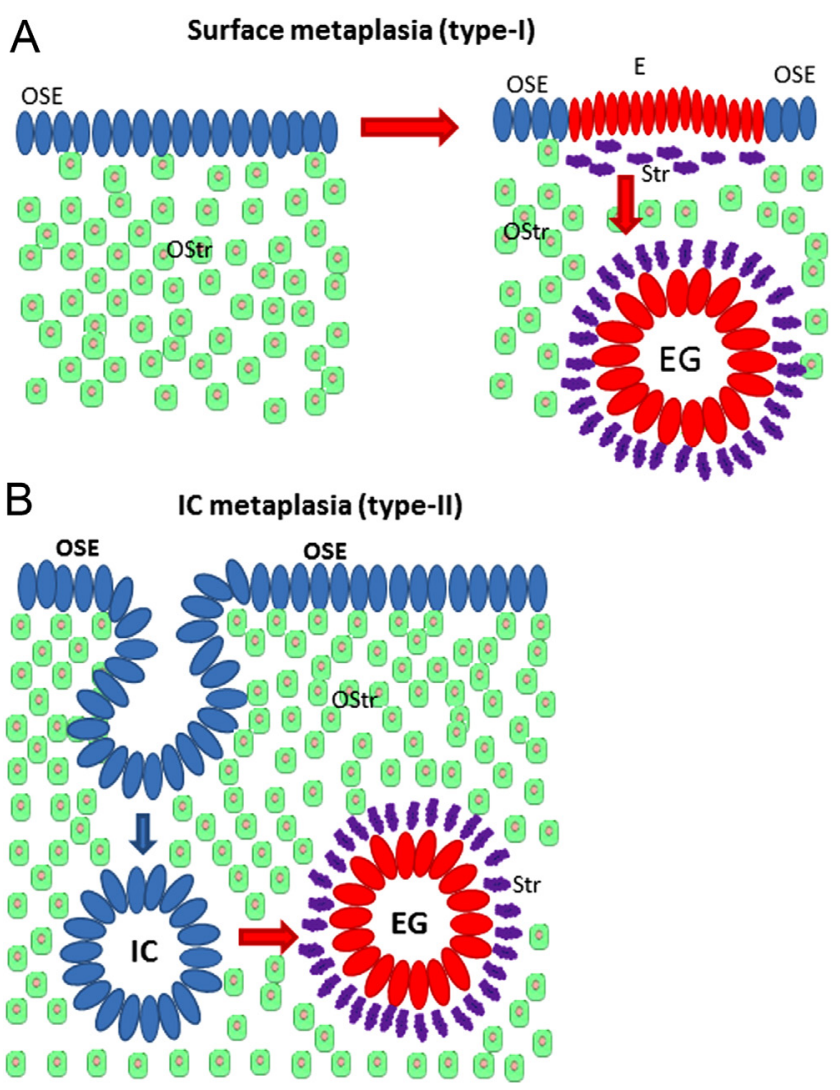

Figure 3 Scheme for ovarian metaplasia leading to endometriosis as proposed by Zheng et al. (2005). (A) OSE cells and the ovarian cortical stroma undergo metaplasia on the ovarian surface, which can result in endometrial glands in the ovarian stroma (OStr). (B) After invagination of the OSE and formation of an inclusion cyst (IC), metaplasia to an endometriotic gland (EG) occurs. E, ectopic endometrial epithel; EG, endometriotic gland; OSE, ovarian surface epithelium; OStr, ovarian stroma; Str, endometrial stroma.

in MRKH and thus suggested metaplasia as a possible cause of endometriosis (Enatsu et al. 2000, Yan \& Mok 2002, Cho et al. 2009, Mok-Lin et al. 2010, Yan et al. 2011, Troncon et al. 2014, Hoo et al. 2016). However, none of the authors presented a hypothesis how metaplasia might happen.

\section{Discussion}

\section{Metaplasia of ovarian epithelial and stromal cells?}

Because in MRKH patients most often endometriomas were found, we will focus on the possibility of ovarian metaplasia. In a study about endometriomas, Zheng et al. (2005) categorized them as type 1 (or initial) when the endometriotic tissue was localized on the ovarian surface between ovarian surface epithelial (OSE) cells but can also form endometrial glands later on (Zheng et al. 2005; Fig. 2D in the reference). Endometrial glands forming inside the ovary after invagination of the OSE and subsequent formation of inclusion cysts were categorized as type 2 (Fig. 3). In addition to histology, 
they performed immunohistochemical analysis and found aromatase-positive epithelial/stromal cells and CD10-positive stromal cells in endometriomas type 1. They concluded that metaplasia did arise from transition of ovarian surface epithelial cells to endometrial epithelial cells and could be observed in endometriomas type 1 (Zheng et al. 2005). Although Zheng et al. (2005) mentioned metaplasia of the ovarian stromal components, no hypothesis was suggested whether the endometriotic stromal cells are generated from OSE or ovarian cortex cells. Recently, however, we could show that nearly all epithelial cells in all endometriomas were positive for keratin 18 and keratin 19 (Konrad et al. 2018a) a protein pattern that has never been found for ovarian surface epithelial cells. Thus, the transition of ovarian surface epithelial cells into endometrial epithelial cells seems highly unlikely as no intermediate cell types between OSE and endometriotic cells could be identified. Similarly, a transition of ovarian cortical or OSE cells to endometriotic stromal cells could not be observed (Konrad et al. 2018b).

Of note, Matsuura et al. (1999) used a coculture system of OSE and ovarian stromal cells in a 3D collagen lattice treated with $17 \beta$ estradiol in which the OSE formed a lumen structure, surrounded by endometrial stromal cells with an epithelial mesenchymal structure. Immunohistochemistry with epithelial membrane antigen and cytokeratin was positive for the glandular cells, which also demonstrated tight junctions. Thus, Matsuura et al. (1999) suggested that endometriosis may manifest as a serial change from the adjacent mesothelial cells. Unfortunately the purity of the OSE by for example calretinin was not evaluated to exclude the possibility of contaminating tubal/endometrial epithelial cells. Furthermore the 'newly' formed endometrial stromal cells were not stained with CD10 to confirm endometriosis of at least the stromal cells.

\section{Discussion of possible metaplasia models}

Although very rarely mentioned, metaplasia of ovarian cells into endometriotic cells requires the differentiation into two distinct cell phenotypes, epithelium and stroma (Fig. 3). However, it still remains unclear whether this process starts from one cell type (e.g. mesothelium) or rather two cell types which then undergo metaplasia into two distinct cell types (stromal and epithelial). If we think about metaplasia of the mesothelium to generate ovarian endometriosis, rectovaginal cells to generate DIE or myometrial muscle cells (or other endometrial cell types) to generate adenomyosis, we have to postulate that in order to become endometrial stromal and endometrial epithelial cells very different cell types in very different surroundings must undergo the same 'endometrial metaplasia' program(s) whose initiating factor(s) are still unknown. Although such a scenario is highly unlikely, it was recently shown that approximately $17 \%$ of cortical ovarian inclusion cysts were paired boxed gene 8 (PAX8)- and calretinin double-positive. This points to metaplasia of calretinin-positive PAX8negative inclusion cysts into PAX8/calretinin doublepositive inclusion cysts (Park et al. 2018). Normally, OSE cells are calretinin -positive and PAX8 negative, whereas the secretory cells of the tubal fimbria are negative for calretinin and positive for PAX8. Although Park et al. (2018) did not analyze the surrounding stroma of the cortical inclusion cysts in detail, no obvious histological characteristics other than ovarian cortical stroma could be seen.

Although metaplasia as a cause of endometriosis is very often mentioned (Nisolle \& Donnez 1997), only very rarely calretinin was used as a marker for peritoneal mesothelial cells or OSE to show metaplasia. To the best of our knowledge, we could identify only four manuscripts where endometriosis was immunohistochemically analyzed with calretinin, but none of them described a positive calretinin staining of endometriomas (McCluggage et al. 2003), liver cysts (Hsu et al. 2014), occult microscopic endometriosis in the peritoneum (Khan et al. 2014) or in a post-cesarean section scar (D'Agostino et al. 2019).

\section{Conclusions}

The best non-invasive choice for the diagnosis of MRKH is MRI, however, in up to $15 \%$ of cases uterus remnants are missed (Preibsch et al. 2014). Thus, in our opinion it is not sufficient to demonstrate uterus agenesis in MRKH patients (Balci et al. 2008, Cho et al. 2009) to be associated with endometriosis without confirmation by biopsy. Exceptional claims need exceptional evidences. We suggest that it is mandatory to present the histology of the uterus/endometrium remnants (if possible) and also from the endometriotic lesions to prove unequivocally uterus agenesis together with endometriosis; otherwise any conclusion of metaplasia is not substantiated. In cases of uncertainty the use of tissue biomarkers such as CD10 for stromal endometrial/endometriotic tissue (McCluggage et al. 2001) or other biomarkers such as calretinin for mesothelial cells (McCluggage et al. 2003) is indicated and conclusive histological pictures together with immunohistochemical evidence should be presented. As clearly shown in this manuscript the claim that the occurrence of endometriosis in MRKH patients is an indication of metaplasia and thus a counterargument to the implantation hypothesis by Sampson is not based on unequivocal proofs. Whenever uterine biopsies were performed endometriosis always appeared together with uterus/endometrium remnants in MRKH cases. Thus MRKH patients only develop endometriosis if a uterus/ endometrium is present which underscores and not contradicts the implantation hypothesis by Sampson. 


\section{Declaration of interest}

The authors declare that there is no conflict of interest that could be perceived as prejudicing the impartiality of this review.

\section{Funding}

This research did not receive any specific grant from any funding agency in the public, commercial or not-for-profit sector.

\section{References}

Acien P 1986 Endometriosis and genital anomalies: some histogenetic aspects of external endometriosis. Gynecologic and Obstetric Investigation 22 102-107. (https://doi.org/10.1159/000298899)

Acien P, Lloret M \& Chehab H 1988 Endometriosis in a patient with Rokitansky-Kuster-Hauser syndrome. Gynecologic and Obstetric Investigation 25 70-72. (https://doi.org/10.1159/000293748)

Balci O, Karatayli R \& Capar M 2008 An incidental coexistence of MayerRokitansky-Kuster-Hauser syndrome with pelvic ectopic kidney and perirenal endometrioma. Saudi Medical Journal 29 1340-1341.

Bulun SE 2009 Endometriosis. New England Journal of Medicine 360 268-279. (https://doi.org/10.1056/NEJMra0804690)

Cho MK, Kim CH \& Oh ST 2009 Endometriosis in a patient with Rokitansky-Kuster-Hauser syndrome. Journal of Obstetrics and Gynaecology Research 35 994-996. (https://doi.org/10.1111/j.14470756.2009.01025.x)

Chun S, Kim YM \& Ji YI 2013 Uterine adenomyosis which developed from hypoplastic uterus in postmenopausal woman with Mayer-RokitanskyKuster-Hauser syndrome: a case report. Journal of Menopausal Medicine 19 135-138. (https://doi.org/10.6118/jmm.2013.19.3.135)

Clement PB 2007 The pathology of endometriosis: a survey of the many faces of a common disease emphasizing diagnostic pitfalls and unusual and newly appreciated aspects. Advances in Anatomic Pathology 14 241-260. (https://doi.org/10.1097/PAP.0b013e3180ca7d7b)

D'Agostino C, Surico D, Monga G \& Palicelli A 2019 Pregnancy-related decidualization of subcutaneous endometriosis occuring in a postcaesarean section scar: case study and review of the literature. Pathology, Research and Practice 215 828-831. (doi:10.106/j.prp.2019.01.024)

Doyle JO \& Laufer MR 2009 Mayer-Rokitansky-Kuster-Hauser (MRKH) syndrome with a single septate uterus: a novel anomaly and description of treatments options. Fertility and Sterility 92 391.e17-391.e19. (https:// doi.org/10.1016/j.fertnstert.2009.03.049)

Elliott JE, Abduljabar H \& Morris M 2011 Presurgical management of dysmenorrhea and endometriosis in a patient with Mayer-RokitanskyKuster-Hauser syndrome. Fertility and Sterility 96 e86-e89. (https://doi. org/10.1016/j.fertnstert.2011.06.006)

Enatsu A, Harada T, Yoshida S, Iwabe T \& Terakawa N 2000 Adenomyosis in a patient with the Rokitansky-Kuster-Hauser syndrome. Fertility and Sterility 73 862-863. (https://doi.org/10.1016/S0015-0282(99)00643-3)

García-Solares J, Donnez J, Donnez O \& Dolmans MM 2018 Pathogenesis of uterine adenomyosis: invagination or metaplasia? Fertility and Sterility 109 371-379. (https://doi.org/10.1016/j.fertnstert.2017.12.030)

Guo SW 2018 Fibrogenesis resulting from cyclic bleeding: the Holy Grail of the natural history of ectopic endometrium. Human Reproduction 33 353-356. (https://doi.org/10.1093/humrep/dey015)

Hall-Graggs MA, Williams CE, Pattison SH, Kirkham AP \& Creighton SM 2013 Mayer-Rokitansky-Kuster-Hauser syndrome: diagnosis with MR imaging. Radiology 269 787-792. (https://doi.org/10.1148/ radiol.13130211)

Hoo PS, Norhaslinda AR \& Shah Reza JN 2016 Rare case of leiomyoma and adenomyosis in Mayer-Rokitansky-Kuster-Hauser syndrome. Case Reports in Obstetrics and Gynecology 2016 3725043. (https://doi. org/10.1155/2016/3725043)

Hsu M, Terris B, Wu TT, Zen Y, Eng HL, Huang WT \& Yeh MM 2014 Endometrial cysts within the liver: a rare entity and its differential diagnosis with mucinous cystic neoplasms of the liver. Human Pathology 45 761-767. (https://doi.org/10.1016/j.humpath.2013.11.005)
Ibrahim MG, Delarue E, Abesadze E, Haas M, Sehouli J, Chiantera V \& Mechsner S 2017 Abdominal wall endometriosis: myofibroblasts as a possible evidence of metaplasia: a case report. Gynecologic and Obstetric Investigation 82 96-101. (https://doi.org/10.1159/000452101)

Kawano Y, Hirakawa T, Nishida M, Yuge A, Yano M, Nasu K \& Narahara H 2014 Functioning endometrium and endometrioma in a patient with Mayer-Rokitansky-Kuster-Hauser syndrome. Japanese Clinical Medicine 5 43-45. (https://doi.org/10.4137/JCM.S12611)

Khan KN, Fujishita A, Kitajima M, Hiraki K, Nakashima M \& Masuzaki H 2014 Occult microscopic endometriosis: undetectable by laparoscopy in normal peritoneum. Human Reproduction 29 462-472. (https://doi. org/10.1093/humrep/det438)

Konrad L, Gronbach J, Horné F, Mecha EO, Berkes E, Frank M, Gattenlöhner S, Omwandho CO, Oehmke F \& Tinneberg HR 2018 a Similar characteristics of the endometrial and endometriotic epithelium. Reproductive Sciences 26 49-59. (https://doi.org/ 10.1177/1933719118756745)

Konrad L, Kortum J, Nabham R, Gronbach J, Dietze R, Oehmke F, Berkes E \& Tinneberg HR $2018 b$ Composition of the stroma in the human endometrium and endometriosis. Reproductive Sciences 25 1106-1115. (https://doi.org/10.1177/1933719117734319)

Kurita T 2011 Normal and abnormal epithelial differentiation in the female reproductive tract. Differentiation; Research in Biological Diversity 82 117-126. (https://doi.org/10.1016/j.diff.2011.04.008)

Lalatta F, Motta F, Restelli E, Bellini M, Miozzo M, Gervasini C, Dallapiccola B, Gentillin B \& Fedele L 2015 Dysmorphological assessment in 115 Mayer-Rokitansky-Küster-Hauser patients. Clinical Dysmorphology $24 \quad 95-101 . \quad$ (https://doi.org/10.1097/ MCD.0000000000000087)

Ledig S \& Wieacker P 2018 Clinical and genetic aspects of MayerRokitansky-Küster-Hauser syndrome. Medizinische Genetik 30 3-11. (https://doi.org/10.1007/s11825-018-0173-7)

Lermann J, Mueller A, Wiesinger E, Häberle L, Brucker S, Wallwiener D, Dittrich R, Renner SP, Beckmann MW \& Oppelt PG 2011 Comparison of different diagnostic procedures for the staging of malformations associated with Mayer-Rokitansky-Küster-Hauser syndrome. Fertility and Sterility 96 156-159. (https://doi.org/10.1016/j.fertnstert.2011.04.051)

Londra L, Chuong FS \& Kolp L 2015 Mayer-Rokitansky-Kuster-Hauser syndrome: a review. International Journal of Women's Health 7 865-870. (https://doi.org/10.2147/IJWH.S75637)

Mahboubi S \& Rostain A 1987 Computed tomography finding in MayerRokitansky-Kuster-Hauser syndrome associated with endometriosis: a case report. Journal of Computed Tomography 11 301-302. (https://doi. org/10.1016/0149-936X(87)90102-0)

Malik E, Mangold R \& Rossmanith WG 1997 Laparoscopic extirpation of an anaplastic ectopic uterus in a patient with Mayer-Rokitansky-KüsterHauser syndrome. Human Reproduction 12 1298-1299. (https://doi. org/10.1093/humrep/12.6.1298)

Marsh CA, Will MA, Smorgick N, Quint EH, Hussain H \& Smith YR 2013 Uterine remnants and pelvic pain in females with MayerRokitansky-Küster-Hauser syndrome. Journal of Pediatric and Adolescent Gynecology 26 199-202. (https://doi.org/10.1016/j.jpag.2012.11.014)

Matsuura K, Ohtake H, Katabuchi H \& Okamura H 1999 Coelomic metaplasia theory of endometriosis: evidence from in vivo studies and an in vitro experimental model. Gynecologic and Obstetric Investigation 47 (Supplement 1) 18-20; discussion 20. (https://doi.org/10.1159/000052855)

McCluggage WG, Sumathi VP \& Maxwell P 2001 CD10 is a sensitive and diagnostically useful immunohistochemical marker of normal endometrial stroma and of endometrial stromal neoplasms. Histopathology 39 273-278. (https://doi.org/10.1046/j.1365-2559.2001.01215.x)

McCluggage WG, Oliva E, Herrington CS, McBride $\mathbf{H}$ \& Young RH 2003 CD10 and calretinin staining of endocervical glandular lesions, endocervical stroma and endometrioid adenocarcinomas of the uterine corpus: CD10 positivity is characteristic of, but not specific for, mesonephric lesions and is not specific for endometrial stroma. Histopathology 43 144-150. (https://doi.org/10.1046/j.13652559.2003.01684.x)

Mok-Lin EY, Wolfberg A, Hollinquist H \& Laufer MR 2010 Endometriosis in a patient with Mayer-Rokitansky-Kuster-Hauser syndrome and complete uterine agenesis: evidence to support the theory of coelomic metaplasia. Journal of Pediatric and Adolescent Gynecology 23 e35-e37. (https:// doi.org/10.1016/j.jpag.2009.02.010) 
Nisolle M \& Donnez J 1997 Peritoneal endometriosis, ovarian endometriosis, and adenomyotic nodules of the rectovaginal septum are three different entities. Fertility and Sterility 68 585-596. (https://doi. org/10.1016/S0015-0282(97)00191-X)

Oppelt PG, Lermann J, Strick R, Dittrich R, Strissel P, Rettig I, Schulze C, Renner SP, Beckmann MW, Brucker S et al. 2012 Malformations in cohort of 284 women with Mayer-Rokitansky-Küster-Hauser syndrome (MRKH). Reproductive Biology and Endocrinology 10 57. (https://doi. org/10.1186/1477-7827-10-57)

Pan HX \& Luo GN 2016 Phenotypic and clinical aspects of MayerRokitansky-Kuster-Hauser syndrome in a Chinese population: an analysis of 594 patients. Fertility and Sterility 106 1190-1194. (https:// doi.org/10.1016/j.fertnstert.2016.06.007)

Park KJ, Patel P, Linkov I, Jotwani A, Kauff N \& Pike MC 2018 Observations on the origin of ovarian cortical inclusion cysts in women undergoing risk-reducing salpingo-oophorectomy. Histopathology 72 766-776. (https://doi.org/10.1111/his.13444)

Parkar RB \& Kamau WJ 2009 Laparoscopic excision of bilateral functioning noncommunicating and rudimentary uterine horns in a patients with Mayer-Rokitansky-Küster-Hauser syndrome and pelvic endometriosis. Journal of Minimally Invasive Gynecology 16 522-524. (https://doi. org/10.1016/j.jmig.2008.11.002)

Patnaik SS, Brazile B, Dandolu V, Ryan PL \& Liao J 2015 Mayer-RokitanskyKüster-Hauser (MRKH) syndrome: a historical perspective. Gene $\mathbf{5 5 5}$ 33-40. (https://doi.org/10.1016/j.gene.2014.09.045)

Preibsch H, Rall K, Wietek BM, Brucker SY, Staebler A, Claussen CD \& Siegmann-Luz KC 2014 Clinical value of magnetic resonance imaging in patients with Mayer-Rokitansky-Küster-Hauser (MRKH) syndrome: diagnosis of associated malformations, uterine rudiments and intrauterine endometrium. European Radiology 24 1621-1627. (https:// doi.org/10.1007/s00330-014-3156-3)

Rall K, Barresi G, Wallwiener D, Brucker SY \& Staebler A 2013 Uterine rudiments in patients with Mayer-Rokitansky-Küster-Hauser syndrome consist of typical uterine tissue types with predominantly basalislike endometrium. Fertility and Sterility 99 1392-1399. (https://doi. org/10.1016/j.fertnstert.2012.12.002)

Raya-Rivera AM, Esquiliano D, Fierro-Pastrana RF, López-Bayghen E, Valencia P, Ordorica-Flores R, Soker S, Yoo JJ \& Atala A 2014 Tissueengineered autologous vaginal organs in patients: a pilot cohort study. Lancet 384 329-336. (https://doi.org/10.1016/S0140-6736(14)60542-0)

Rosenfeld DL \& Lecher BD 1981 Endometriosis in a patient with Rokitansky-Kuster-Hauser syndrome. American Journal of Obstetrics and Gynecology 139 105. (https://doi.org/10.1016/0002-9378(81)90418-X)
Sampson JA 1927 Peritoneal endometriosis due to menstrual dissemination of endometrial tissue into the peritoneal cavity. American Journal of Obstetrics and Gynecology 14 422-469. (https://doi.org/10.1016/ S0002-9378(15)30003-X)

Sönmezer M, Atabekoglu C \& Dökmeci F 2003 Laparoscopic excision of symmetric uterine remnants in a patient with Mayer-RokitanskyKüster-Hauser syndrome. Journal of the American Association of Gynecologic Laparoscopists 10 409-411. (https://doi.org/10.1016/ S1074-3804(05)60275-7)

Troncon JK, Zani AC, Vieira AD, Poli-Neto OB, Nogueira AA \& Rosa-ESilva JC 2014 Endometriosis in a patient with Mayer-Rokitansky-KüsterHauser syndrome. Case Reports in Obstetrics and Gynecology 2014 376231. (https://doi.org/10.1155/2014/376231)

Wang Y, Lu J, Zhu L, Sun Z, Jiang B, Feng F \& Jin Z 2017 Evaluation of Mayer-Rokitansky-Küster-Hauser syndrome with magnetic resonance imaging: three patterns of uterine remnants and related anatomical features and clinical settings. European Radiology 27 5215-5224. (https://doi.org/10.1007/s00330-017-4919-4)

Will MA, Marsh CA, Smorgick N, Smith YR \& Quint EH 2013 Surgical pearls: laparoscopic removal of uterine remnants in patients with MayerRokitansky-Kuster-Hauser syndrome. Journal of Pediatric and Adolescent Gynecology 26 224-227. (https://doi.org/10.1016/j.jpag.2013.03.004)

Yan CM \& Mok KM 2002 Uterine fibroids and adenomyosis in a women with Rokitansky-Kuster-Hauser syndrome. Journal of Obstetrics and Gynaecology 22 561-562. (https://doi.org/10.1080/0144361021000003780)

Yan L, Zhao X \& Qin X 2011 MRKH syndrome with endometriosis: case report and literature review. European Journal of Obstetrics, Gynecology, and Reproductive Biology 159 231-232. (https://doi.org/10.1016/j. ejogrb.2011.06.010)

Zheng W, Li N, Wang J, Ulukus EC, Ulukus M, Arici A \& Liang SX 2005 Initial endometriosis showing direct morphological evidence of metaplasia in the pathogenesis of ovarian endometriosis. International Journal of Gynecological Pathology 24 164-172. (https://doi.org/10.1097/01. RCT.0000157091.37057.B4)

Received 5 July 2018

First decision 7 September 2018

Revised manuscript received 11 March 2019

Accepted 11 April 2019 